\title{
Questes
}

\section{Le surnom du prince : la construction de la mémoire historique par un Rhétoriqueur}

\section{Estelle Doudet}

\section{(2) OpenEdition}

1 Journals

\section{Édition électronique}

URL : http://journals.openedition.org/questes/2597

DOI : 10.4000/questes. 2597

ISSN : 2109-9472

Éditeur

Les Amis de Questes

\section{Édition imprimée}

Date de publication : 15 décembre 2002

Pagination : 6-7

ISSN : 2102-7188

\section{Référence électronique}

Estelle Doudet, "Le surnom du prince : la construction de la mémoire historique par un Rhétoriqueur », Questes [En ligne], 2 I 2002, mis en ligne le 01 janvier 2014, consulté le 15 septembre 2020. URL: http://journals.openedition.org/questes/2597

\section{(c) Association des amis de «Questes »}


sont classés par ordre et par incipit : on retiendra la mélodie caractéristique du premier mode en chantant la formule «Primum quaerite Regnum Dei », celle du troisième grâce à «Tertia die est quod haec facta sunt». Pensons également aux notes de la gamme (Ut, ré, mi, fa, sol, la) que l'apprenti cantor pouvait mémoriser grâce à l'hymne à Saint Jean Baptiste.

La diffusion viva voce du répertoire grégorien, ainsi que la technique de la centonisation (qui revient à inventer une pièce nouvelle à partir de diverses cellules préexistantes) impliquent une mémoire extrêmement dynamique, où transmission, improvisation et création s'interpénètrent. Une telle mémoire ne pouvait être que protéiforme, faisant appel à l'ouïe (mémoire naturelle, jeux d'incipit, de rimes et d'assonances), à la vue (l'architecture des églises et des abbayes, leur décoration, en fait des lieux de rémanence mémorielle autant que de résonance acoustique), voire au toucher (solmisation dite " guidonienne », chironomie). Ce qui rend le mieux l'aspect synesthésique de cette mémoire médiévale est en définitive le geste musical, geste reçu comme une écriture intérieure.

(Article complet sur le site de Questes : http://questes.free.fr)

\section{Estelle DOUDET, «Le surnom du prince : la construction de la mémoire historique par un Rhétoriqueur»}

La pratique du surnom donné au prince tend à s'intensifier et à se diversifier dans l'historiographie des derniers siècles médiévaux. Les indiciaires bourguignons aiment à gloser le nom de leur commanditaire ducal, consonnes et voyelles qui forment comme l'alphabet des vertus. George Chastelain (1415-1475), premier d'entre eux, préfère inventer pour la postérité des surnoms qui constitueront le prince en figure littéraire.

Le chapitre 41 du Livre II de la Chronique (édition Kervyn de Lettenhove, Bruxelles, 1866-1869, tome II, pp.148-151) se présente comme un texte habilement construit dans ce but. La narration événementielle se transforme, grâce à l'insertion ironique d'une vox populi incongrue (les quenouilles des vieilles), en exploration de l'adage que c'est dans les aléas de Fortune que resplendit le mieux la gloire du prince. Chastelain glisse vers l'invention d'un premier surnom pour Philippe le Bon : «Auguste ». Le choix est motivé par des raisons historiques (Philippe II « Auguste » de Bourgogne est le digne descendant de Philippe II «Auguste» de France), rhétoriques (Chastelain, historiographe de la Bourgogne du $\mathrm{XV}^{\mathrm{e}}$ siècle concurrence Rigord et l'historiographie dyonisienne officielle du XII ${ }^{\mathrm{e}}$ siècle), symboliques (le signe astrologique de Philippe est le lion, qui est aussi son symbole héraldique et sa principale métaphore dans l'œuvre de Chastelain...).

Mais le travail du Rhétoriqueur ne s'arrête pas à ce résultat déjà satisfaisant. Chastelain ajoute une autre vox populi inattendue, «les sarrazines voix» qui «clament [Philippe] le grand duc du Ponant». L'Orient est convoqué pour parer le 
duc d'un second surnom, dont le prestige efface cette fois la puissance capétienne et le lignage - surnom naturellement inventé de toute pièce par Chastelain lui-même. Ainsi la rhétorique «auguste » de l'historiographe augmente la gloire de l'Auguste duc, en soulignant la singularité d'un prince, unique en son temps. L'écriture se constitue, dans le même mouvement, en source d'elle-même : le lion de Bourgogne, le grand duc d'Occident renvoient, en fait, à l'écriture de Chastelain et participe à sa gloire. Le nom du prince est remplacé par le surnom littéraire dans la mémoire des hommes, signe de la complicité de l'écrivain et de son commanditaire qui caractérise l'œuvre des premiers Rhétoriqueurs.

\section{Mickaël WILMART, « Les fondations pieuses et la construction de la mémoire. Le cas de Jean Rose, bourgeois de Meaux du XIV ${ }^{\mathrm{e}}$ siècle »}

Au delà de l'aspect religieux reflétant la piété du bienfaiteur, doter une église ou un établissement ecclésiastique, fonder une messe ou mieux une institution de charité sont des actions qui s'inscrivent dans un phénomène plus vaste de construction de la mémoire de l'individu. Sa générosité assure, outre le salut de son âme, la postérité d'une bonne réputation. Cette mémoire prend en premier lieu la forme de l'écrit : les obituaires dressent la liste des offices pour les donateurs, conservant ainsi leurs noms que les générations suivantes continueront à honorer pour leurs bienfaits.

Il arrive parfois que la richesse d'un homme l'aide à dépasser la mémoire écrite pour une mémoire de la pierre se dessinant dans le paysage urbain. Ainsi, Jean Rose, bourgeois de Meaux (Seine-et-Marne) mort en 1364, est devenu à travers les siècles le héros de toute une ville. A la mort de son père, Jean Rose hérite de la plus grande fortune de Meaux. Au XIII ${ }^{\mathrm{e}}$ siècle, ses ancêtres étaient des drapiers et c'est sans doute dans cette activité qu'il faut en chercher l'origine. Cette richesse, apparemment largement supérieure à celles de ses concitoyens, permet à Jean Rose de faire de nombreuses fondations pieuses. Surtout, elle va faire de lui un bâtisseur.

Son épouse Jeanne meurt en 1328. A partir de cette date, il accumule des biens en vue de fonder une chapelle dans la cathédrale. Alors que dans la plupart des villes, les bourgeois fondent l'office de la chapelle ou/et financent les ornements ou les vitraux, Jean Rose donne l'argent nécessaire à sa construction. En 1331, la nouvelle chapelle collatérale de la cathédrale est achevée et on y installe l'autel du SaintSacrement. Cette installation n'est sans doute pas anodine dans la construction d'une mémoire si on prend en considération l'importance de la dévotion des fidèles au Saint-Sacrement. Or, Jean Rose fait de cette chapelle «sa» chapelle. Dans un premier temps il y place la sépulture de son épouse décédée et y prévoit la sienne. A cette fin, on réalise la pierre tombale du couple, toujours conservée dans la cathédrale, qui fait apparaître un raffinement supérieur à celui des tombes ecclésiastiques du sanctuaire. La dalle se caractérise par sa polychromie composée d'un calcaire carbonifère noir incrusté de marbre blanc et d'un mastic coloré dessinant 